\title{
Spiritual needs as experienced by Muslim patients in Iran: a
} qualitative study

\author{
Mansooreh Karimollahi*1, Heidar Ali Abedi² ${ }^{2}$ and Alireza Yousefy ${ }^{3}$
}

Address: ${ }^{1}$ Ardabil Medical Sciences University, Ardabil, Iran, ${ }^{2}$ Faculty of Nursing \& Midwifery, Islamic Azad University, Khorasgan Branch And Medical Education Research Centre (MERC) of Isfahan University of Medical Sciences, Isfahan,Iran and ${ }^{3}$ Medical Education resource center, Esfahan Medical Sciences University, Isfahan, Iran

* Corresponding author

from International Society on Brain and Behaviour: 3rd International Congress on Brain and Behaviour

Thessaloniki, Greece. 28 November - 2 December 2007

Published: 17 April 2008

Annals of General Psychiatry 2008, 7(Suppl I):SI47 doi:I0.II86/I744-859X-7-SI-SI47

This abstract is available from: http://www.annals-general-psychiatry.com/content/7/SI/SI 47

(c) 2008 Karimollahi et al.; licensee BioMed Central Ltd.

\section{Background}

Until the last 2 decades, spiritual care was a vital, but invisible, aspect of nursing care. Spirituality and spiritual care have entered the mainstream, and the literature in this area has burgeoned. In addition, there is minimal information in the literature documenting the expressed spiritual needs of patients in general and specific subgroups of patients in particular, thus this article aimed to present spiritual needs of Iranian Muslim patients. Therefore, this study is of significance to nursing in general and to transcultural nursing in particular because of the high priority associated with increasing the nursing knowledge through research that investigates and describes care practices in diverse cultures.

This paper reports an investigation into the spiritual needs of hospitalized Iranian Muslim patients.

\section{Materials and methods}

Qualitative study with a sample of 24 patients using semistructured interviews. The sample selected from three different cities of Iran

\section{Results}

Although not clearly distinguishable, we found two main spiritual needs include religious and existential needs in Iranian Muslim patients.

\section{Conclusions}

With regard to holistic approach in Islamic philosophy, holism is a relevant concept in the care of Iranian patients. 